revista do ieb n 46 p. 217-240 fev 2008

\title{
Taunay viajante: uma contribuição para a historiografia literária brasileira
}

Olga Maria Castrillon-Mendes ${ }^{1}$

Resumo

Neste texto proponho analisar a obra de Alfredo D'Escragnolle Taunay, o Visconde de Taunay, especificamente a imagética de Mato Grosso nas descrições da viagem feita durante a Campanha da Laguna, na Guerra da Tríplice Aliança contra o Paraguai (1864-1870). Procuro, nesta investigação, penetrar no universo particular do escritor, focando a idéia de identidade nacional no século XIX e de como as noções de Natureza/Paisagem/Viagem/Imagens literárias entram nas abrangentes discussões de um Romantismo de transição, cujo legado teve fecunda influência na formação intelectual de Taunay e nos rumos das tendências estéticas brasileiras.

\section{Palavras-chave}

Visconde de Taunay, identidade nacional, natureza, Romantismo

1 Professora de Literatura do Departamento de Letras da UNEMAT/Cáceres. Membro do Instituto Histórico e Geográfico de Cáceres (IHGC) e do Grupo RG Dicke de Estudos em Cultura e Literatura de Mato Grosso (CNPq/UFMT). 
revista do ieb n 46 p. 217-240 fev 2008

\section{Taunay, the traveller: a contribution to Brazilian literary history}

Olga Maria Castrillon-Mendes ${ }^{1}$

\section{Abstract}

In this text I intend to analyse the Alfredo D'Escragnolle Taunay's work, the Viscount of Taunay, particularly the imagetic of Mato Grosso in the traveling descriptions of the Laguna Campaign, during the Paraguay War (1864-1870). In this investigation, I intend to find out the Author's particular universe, focusing on the idea of national identity in the XIX century and on how the notions of Nature, Landscape, Travel and literary Images come into the discussions of a transition Romanticism, with the purpose of studying Taunay's intellectual formation as well as the Brazilian aesthetic tendencies.

Keywords

Viscount of Taunay, national identity, nature, Romantism 
Desde o século XVII na América, os portugueses avançaram em terras espanholas, empurrando a linha de Tordesilhas, e bandeirantes paulistas penetraram nos sertões de Goiás, Paraná, Santa Catarina, Rio Grande do Sul e Mato Grosso. A descoberta do ouro, em Cuiabá, ocasionou a necessidade de fixação dos núcleos populacionais. Dessa forma, os rios transformaram-se em caminhos das monções ${ }^{2}$, que saíam de São Paulo pelo rio Tietê. Esta via fluvial, com a singularidade de nascer junto ao mar e correr para o interior em busca das águas do Paraná, facilitou a interiorização das expedições monçoeiras, revigorou a presença branca na área $e$ assegurou a supremacia portuguesa além de Tordesilhas.

Nesse processo histórico, o espaço geográfico onde se configurou Mato Grosso, até a sua divisão em $1978^{3}$, foi delimitado pela formação de povoamentos, vilas e fortificações. Em 1748, quando da criação da Capitania, desmembrada de São Paulo, seus contornos iam de Camapuã (no sul) a Guaporé (no extremo oeste) e se imprimia como chave e propugnáculo dos sertões do Brasil, conforme consta nos documentos administrativos da Colônia. Podemos dizer que Mato Grosso é parte do projeto iluminista na concepção e no espírito renovador do Marquês de Pombal, figura tida por Antonio Candido como de

ação decisiva e benéfica para o Brasil, favorecendo atitudes mentais esclarecidas que incrementariam o desejo de saber, a adoção de novos pontos de vista na literatura e na ciência, certa reação contra a tirania intelectual do clero e, finalmente, o nativismo. ${ }^{4}$

Tais ações, direta ou indiretamente, deitariam raízes na transformação da sociedade, mesmo com os fortes laços de interesse e de comprometimento ideológico.

Com os olhos voltados para esse arraigamento, vê-se uma Europa de inícios do século XIX dominada por padrões franceses; no mundo hispano-americano, o desejo de independência, o antagonismo de interesses e a indefinição do ideário de nação colocam os países frente a problemas de política externa, de navegação e de fronteiras, em que se reaquecem antigas desa-

2 Expedições em barcos de provisão que conseguiam varar os locais inundáveis e de difícil acesso.

3 Sobre a divisão do Estado de Mato Grosso, cf. CAMPESTRINI \& GUIMARÃES. História de Mato Grosso do Sul. Campo Grande-MS: Academia Sul-MatoGrossense de Letras, 1991 e VALLE, Pedro. A divisão de Mato Grosso. Brasília: Royal Court, 1996.

4 CANDIDO, Antonio [1957]. Formação da Literatura Brasileira (momentos decisivos). 8. ed. Belo Horizonte-Rio de Janeiro: Itatiaia, 1997. v. 1 (1750-1836), p. 63. 
venças entre "vizinhos indigestos" 5 e os tratados de limites são colocados em xeque. Em conseqüência, a diplomacia entre os países não funciona a contento, e o impasse pela livre utilização dos rios, para não isolar Mato Grosso, chega ao limite do inegociável. Assim, explode o confronto na região do Prata, no momento de consolidação dos estados nacionais latino-americanos.

Nesse período, Alfredo d'Escragnolle Taunay chega a Mato Grosso pela sua parte sul, compondo a malograda expedição militar contra os paraguaios. Sua função é relatar os acontecimentos da guerra, encargo que lhe proporcionou as observações mais pungentes da batalha e do sertão, onde os pantanais ameaçavam tragar os homens. Tinha, então, 21 anos. Seus relatos parecem compor o que Manthorne ${ }^{6}$ chama de "cultura de viagem”, textos que, aliados a outros escritos elaborados por diferentes observadores sociais, formam uma literatura fundamental para a nossa constituição de povo, de raça e de processos ideológicos. São, portanto, registros que prenunciam como o século XIX recorta o mundo e como as imagens escritas e desenhadas por outros olhares se mesclam com a paisagem do interior brasileiro para construir outro mundo sobre aquele já existente e prenhe de significação.

Dessa forma, tem-se, de um lado, o olhar identitário que tende a representar um tempo de transformações sociais e econômicas, a crise do regime escravista e da imigração; de outro, as lutas para a consolidação de um Estado Imperial que garantisse a Soberania Nacional, animado pelo ideal de progresso e sentimento da polis. Ou, no dizer de Candido ${ }^{7}$, o "nativismo" - no sentido de contribuição para o progresso e afirmação do "próprio" contra o "imposto" -, em cuja manifestação de costumes, paisagens e sentimentos se define o desejo de individuação nacional.

O locus dos acontecimentos discursivos concentra, assim, uma rica metamorfose com os elementos encontrados no outro, que é o lugar da diferença. Esse fato cria a sensação de "não estar de todo", tema tomado por Flora Sussekind ${ }^{8}$ e desenvolvido

5 Tomamos a expressão de MENEZES, Alfredo da Mota. Guerra do Paraguai: como construímos o conflito. São Paulo: Contexto; Cuiabá-Mato Grosso: Ed. da UFMT, 1998.

6 MANTHORNE, Katherine. 0 imaginário brasileiro para o público norte-americano do século XIX. Revista USP. Dossiê Brasil dos Viajantes, São Paulo, n. 30, jun/ago, p. 58-71, 1996.

7 CANDID0, Antonio [1957]. Formação da Literatura Brasileira (momentos decisivos). 8. ed. Belo Horizonte-Rio de Janeiro: Itatiaia, 1997. v. 2 (1836-1880), p. 11-21.

8 SUSSEKIND, Flora. O Brasil não é longe daqui: o narrador, a viagem. São Paulo: Companhia das Letras, 1990. 
amplamente na condição do impacto e do confronto por Julia Kristeva9. Trata-se de um sentimento de "desconforto do lugar de não-origem", que possibilita a (re)criação de novos paradigmas para os sistemas de pensamento, fornecendo ao escritor os discursos de suas próprias tramas que criam o espaço de intersecção no processo de construção/superposição das imagens. Não como ponto fixo, mas construção móvel de caminhos que não diluem a perspectiva de outros olhares, ao contrário, a conjunção deles dá ao domínio do corpus uma abrangência para além do regional.

Alfredo Taunay, brasileiro de nascimento, descendia de uma família de eminentes artistas franceses, vindos para o Brasil a fim de fundar a Academia Imperial das Belas-Artes, no Rio de Janeiro. Nesse momento, a Monarquia portuguesa buscava dotar de condições a antiga colônia, para transformá-la em sede do governo, tendo o período de transição e de consolidação da Corte portuguesa funcionado como atrativo para estrangeiros de várias partes da Europa. No entanto, a criação de uma Academia de Artes, responsável também pelo ensino de alguns ofícios, adquiria uma importância mais política do que propriamente artística, mas de profundas interferências nos rumos da arte no Brasil.

Os artistas franceses, em sua maioria bonapartistas ${ }^{10}$, trouxeram uma organização racional do ensino. A base seria o desenho, "partindo-se sempre de seu tronco que é a pintura de história; os professores deveriam enfatizar o aprendizado a partir das cópias d'après moldagens do antigo e de modelo vivo". Nesse aspecto, Nicolas Taunay, muito considerado, nos meios europeus, como talentoso pintor, garantiu a permanência dos Taunay no Brasil através de sua descendência artística. Em depoimento memorialístico, Alfredo Taunay diria que "de espírito melancólico e tímido, este meu avô, [...] tinha mérito real na pintura histórica e de paisagem e conseguiu, pela assiduidade e consciência, lugar de nota na Escola Francesa"11.

Dentre os filhos que acompanharam Nicolas na Missão Artística, dois tiveram fortes ligações com a literatura de Alfredo Taunay: o tio Aimé-Adrien Taunay e o pai Félix Émile

9 KRISTEVA, Júlia. Estrangeiros para nós mesmos. Trad. Maria Carlota Carvalho Gomes. Rio de Janeiro: Rocco, 1994.

$10 \mathrm{Cf}$. os curiosos argumentos sobre a polêmica da instalação e do papel da Missão Artística Francesa no Brasil in: LIMA, Valéria Alves de. Academia Imperial das Belas-Artes: um projeto político para as artes no Brasil. 1994. Dissertação (Mestrado em História) - Instituto de Filosofia e Ciências Humanas, Universidade Estadual de Campinas, 1994, especialmente o cap. 1.

11 TAUNAY, Alfredo d'Escragnolle. Memórias do Visconde de Taunay. São Paulo: Melhoramentos, 1948. p. 202. 
Taunay, de quem foi discípulo infatigável, como afirmou Wanderley Pinho, numa conferência realizada no Instituto Histórico e Geográfico Brasileiro, em 22 de novembro de 1943:

é recorrer à correspondência entre ambos, é ver o velho Taunay a corrigir o francês das cartas do filho que partira para a guerra, a recomendar-lhe leituras, enviando-lhe livros como o de Ricardo sobre botânica, o do Tio Charles em latim e mais álbuns e modelos de desenhos. ${ }^{12}$

A par de tamanha força de origem, Alfredo Taunay se emanciparia de tais influências?

Defendo a hipótese de que a viagem a Mato Grosso, na Campanha contra o Paraguai, foi fundamental para a sua aquisição de liberdade, do gosto, da expressão, da criação de um estilo próprio e de encaminhamentos do exercício artístico. Não era mais o menino levado pelo pai, mas o oficial que marchava para a guerra,

todo cheio de idéia de ir viver bem sobre mim, entregue ao prazer de ver gentes e cidades novas, percorrer grandes extensões e varar até sertões imperfeitamente conhecidos e mal explorados. ${ }^{13}$

Dessa forma, a viagem funcionou como um instrumento de transformação do jovem militar em escritor. Uma contingência que despertava prazer, conhecimento e

inúmeros atrativos e grandioso prestígio, a que se uniam pretensões científicas de certo alcance, fazer coleções de minerais preciosos, ou então descobrir, senão um gênero novo de planta, pelo menos uma espécie ainda não estudada e classificá-la - sonhos enfim de mocidade em que havia bastante de pedantismo. ${ }^{14}$

Assim, sem um projeto de viagem (principalmente a que fez a Mato Grosso), movido pelo cumprimento do dever, pela aventura, pela busca do conhecimento e, possivelmente, pelo desejo de fama, Alfredo Taunay foi um viajante singular, pois, além de

12 PINHO, Wanderley. Visconde de Taunay. Revista do Instituto Histórico e Geográfico Brasileiro, Rio de Janeiro, n. 181, p. 5-43, out./dez. 1943. p. 6.

13 Cf. TAUNAY, Alfredo d'Escragnolle. Memórias do Visconde de Taunay. São Paulo: Melhoramentos, 1948. p. 105.

14 Ibid. p. 6. 
cumprir o papel de militar e de viajante vinculado à tradição da viagem, constituiu-se um esteta. Numa elaboração constante do olhar, afirmou os temas locais numa expressão particularizada do Brasil. Como relator da Comissão de Engenheiros fez o papel de diarista, colheu informações e anotou impressões da viagem e da guerra, exercício que lhe possibilitou a produção de toda a sua literatura. Vincula-se, assim, ao "entusiasmo romântico" e ao exercício da observação da natureza transformada em paisagem, o que define o papel da arte como "auxiliar das ciências naturais", pois só se pode conhecer viajando, e a natureza é o laboratório das experiências do viajante ${ }^{15}$. Esse entusiasmo dá suporte de arte às narrativas, num período histórico culturalmente rico de construção da identidade nacional, nem sempre afirmada pacificamente.

Busca-se, desta forma, compreender os processos significativos que resultaram dessas diferentes reimpressões e caracterizar o escritor como um viajante atípico que agiu como um explorador, porém mais preocupado com a impressão de imagens esteticamente válidas para os propósitos nacionais. Ao tomar contato com o interior de Mato Grosso, Taunay fez-se um (d)escritor da natureza transformada em paisagem, compondo uma imagem descritiva da região que, juntamente com outras imagens construídas pela Monarquia brasileira, representaria a vontade consciente de definir a idéia de um Brasil homogêneo, mesmo que essa unidade figurasse como uma utopia nacional.

\section{Taunay e a historiografia literária brasileira}

Nos anos 50/60 do século XIX, o cenário político brasileiro teve fecundas transformações e a extinção do tráfico dos negros gerou um período de crises no regime de governo e nas instituições que o sustentavam. Já não vigoravam somente as atitudes do eu romântico incapaz de resolver os problemas das diferenças sociais, ou os suspiros poéticos, as saudades, os códigos clássicos, a exacerbação religiosa, a criação idealizada do herói e da natureza, mas o contato direto pela observação de uma cultura citadina e letrada que se antepunha à matéria bruta do sertão de um Brasil mais rural, provinciano e arcaico, como diz Alfredo Bosi ${ }^{16}$. Perguntava-se, então, continua o crítico, se esse era o verdadeiro Brasil ou se existiriam outros, "o da face

15 DIENER, Pablo. La estética clasicista de Humboldt aplicada al arte de los viajeros. Amerística, México, DF, año 2, n. 3, p. 41, segundo semestre de 1999.

16 BOSI, Alfredo. História concisa da literatura brasileira. São Paulo: Cultrix, 1988. p. 155. 
culta" da metrópole carioca e das capitais de algumas Províncias e "o da face oculta", diferenciada, contudo não menos necessária ao projeto de integração nacional. Uma parte desse Brasil da "face oculta" foi representada por Alfredo Taunay.

Construindo-se personagem da história política e literária brasileira, Taunay carrega o que Sílvio Romero ${ }^{17}$ designa de "germes de origem". Um deles é o de paisagista, "inoculado[s] desde o berço e reforçado[s] [...] pelos espetáculos inolvidáveis dos múltiplos panoramas do Rio de Janeiro, [...] sob a indicação do dedo mestre do pai”; o outro é o de escritor, pela "ação poderosíssima de longas e custosíssimas viagens pelo grande oeste pátrio, por São Paulo, Minas, Goiás e Mato Grosso, feitas [...] aos vinte e dois anos [...]". Conhecer o pensamento do período do qual estamos tratando é conviver com uma parcela da forma como se pensava o Brasil, mesmo que Taunay (meio francês, meio brasileiro) possa significar uma espécie de contradição que, segundo Romero ${ }^{18}$, parece intrínseca e fundamental para compreender a causa de suas lutas pela imigração e contra a escravidão.

Um panorama historiográfico pode dar conta da compreensão desse universo de construção literária.

Situando a prosa romântica, Nelson Werneck Sodré ${ }^{19}$ diz que o "verdadeiro Brasil", original, puro, seria o do interior, o do sertão, "imune às influências externas, conservando em estado natural os traços nacionais". Não por acaso, o índio foi focalizado como emblema nacional e, posteriormente, não representando mais a totalidade de caráter dessa expressão, foi substituído, mesmo que não totalmente, pelo sertanejo, trabalhador da terra e em harmonia com o cenário natural, e também romântico, embora carregado de outros aspectos singulares.

No estudo sobre "três romancistas de costumes rurais", Lúcia Miguel Pereira ${ }^{20}$ defendeu a tese - "duvidosa” para Afrânio Coutinho ${ }^{21}$ - da supremacia dos costumes sertanejos sobre as personagens da obra Inocência. Para ele, o romance aponta "sérios

17 ROMERO, Sílvio. 0 Visconde de Taunay (o homem de letras). In: Estudos de literatura contemporânea (edição comemorativa); Rio de Janeiro: Imago; Aracaju-SE: UFS, 2002. p. 407.

18 Ibid.

19 SODRÉ, Nelson Werneck. História da Literatura Brasileira: seus fundamentos econômicos. 3. ed. Rio de Janeiro: José Olympio, 1960. p. 298-299.

20 PEREIRA, Lúcia Miguel. Três romancistas regionalistas: Franklin Távora, Taunay e Domingos Olímpio. In: O romance brasileiro (de 1752 a 1930). Rio de Janeiro: Ed. de 0 Cruzeiro, 1952.

21 CoUTINHO, Afrânio (Dir.). A Literatura no Brasil. Rio de Janeiro: Ed. SulAmericana, 1955. v. 1, t. 2, p. 07 e 110. 
defeitos de técnica, complexidade e mistério", apesar de o escritor conseguir criar um "mundo próprio das personagens". Por outro lado, Antonio Candido diz ser "mediano" o nosso escritor, mas ao mesmo tempo, um "caso raro na literatura do tempo, para a qual trouxe uma rica experiência de guerra e de sertão, depurada por sensibilidade e cultura nutridas de música e artes plásticas" ${ }^{22}$.

Como visto, as opiniões a respeito do conjunto da obra variam muito e não encontram muita guarida entre os críticos, incluindo os contemporâneos. Pressupõe-se que ocorre certo desconhecimento sobre a contribuição da obra de Alfredo Taunay para a anexação do conceito de interior brasileiro, com as descrições de cidades, campos, da natureza e do homem. Trata-se de um exercício do olhar que tornou visível o espaço desconhecido, mas também marcou uma forma de apropriação, estabelecendo uma história que se fez pelo imaginário. Neste caso, o discurso da descoberta foi acentuado, posteriormente, pela elaboração das lembranças da guerra, da política imperial, da persona do Imperador e dos acontecimentos nacionais do Segundo Império.

0 que Antonio Candido analisa como peculiaridade cultural Sílvio Romero reconheceu, nas raízes do pensamento de Alfredo Taunay, como "sentimento de paisagem" que se sobreleva à imaginação, ao vigor e à poesia, quando comparado o escritor a românticos como Alencar - julgamento que foi seguido por quase toda uma geração de críticos.

Com José Veríssimo, a obra de Alfredo Taunay aparece como "fórmula" literária e "cópia" em que falta "coesão e intensidade que lhe dessem mais solidez e distinção" "23, o que, para Afrânio Coutinho, faz com que o escritor se perca "na descrição da natureza, nas anotações dos costumes e, talvez, na excessiva preocupação de fidelidade [...], do que resulta certa falta de unidade, certo desequilíbrio no tônus do romance" ${ }^{24}$. Nesse aspecto, Olívio Montenegro coloca-se ao lado de Coutinho ao considerálo mais um homem de ciência do que puro escritor. Montenegro ressalta, ainda, o descritivismo, a "maníaca cor local" ou "os dois olhos de Narciso" ${ }^{25}$ do romance Inocência.

22 CANDID0, Antonio [1957]. Formação da Literatura Brasileira (momentos decisivos). 8. ed. Belo Horizonte-Rio de Janeiro: Itatiaia, 1997. v. 2 (18361880), p. 266 e 275.

23 Cf. VERÍSSIMO, José [1916]. História da Literatura Brasileira (de Bento Teixeira a Machado de Assis). 5 Ed. Rio de Janeiro: José Olympio, 1969. p. 214.

24 CoUTINHO, Afrânio (Dir.). A Literatura no Brasil. Rio de Janeiro: Ed. SulAmericana, 1955. v. 1, t. 2, p. 906.

25 MONTENEGRO, Olívio. 0 romance brasileiro. $2^{\text {a }}$ ed. Rio de Janeiro: José Olympio, 1953. p. 72-78. 
Outros críticos não descem às minúcias dos anteriores e contentam-se em trazer a obra de Taunay, mesmo com as repetições que se sucedem, como representativa do "pitoresco da paisagem e da língua" ${ }^{26}$. Ronald de Carvalho defende o artista como conhecedor da "justa medida das cousas" ${ }^{27}$. Para ele, com Inocência,

começou o romance de amor a perder aquele sainete puramente sentimental que lhe imprimira Macedo [...], desenhando as paixões com menos violência e as figuras com mais naturalidade do que era comum.

João Ribeiro destaca alguns “traços novos” que compõem a fisionomia de Taunay, como as suas ligações com a Arte, o epos contido em A retirada da Laguna e a "suavidade de estilo"28 de Inocência.

A partir desses posicionamentos iniciais, a historiografia literária começa a visualizar outros aspectos da obra do escritor, reunindo ingredientes do contexto (aqui entendido como o conjunto das idéias e o diálogo entre textos). José Aderaldo Castello $^{29}$, lançando mão das Memórias do Visconde de Taunay, demonstra como o escritor obteve elementos essenciais para a elaboração de Inocência e como esta obra está imbricada em outras, como Viagem de regresso e Céus e terras do Brasil. Numa pequena nota, em Presença da Literatura Brasileira ${ }^{30}$, Castello diz, em conjunto com Antonio Candido, que Taunay é "sobretudo, visual, primando nas descrições; mesmo a sua narrativa, freqüentemente muito boa, se traduz em termos plásticos" (grifamos).

Vai-se, dessa forma, afunilando uma visão menos formal de um regionalismo artificial, para se compreenderem os elementos constituidores do nacionalismo literário brasileiro que consistiu, basicamente, em "escrever sobre coisas locais" rumo a uma "intenção programática, a resolução patriótica de fazê-

26 MONTENEGRO, Olívio. 0 romance brasileiro. $2^{\text {a }}$ ed. Rio de Janeiro: José Olympio, 1953. p. 301.

27 CARVALHO, Ronald de. Pequena História da Literatura Brasileira. 6 ed. Rio de Janeiro: Briguiet, 1937. p. 262.

28 RIBEIR0, João. Critica (clássicos e românticos brasileiros). Rio de Janeiro: Ed. da Academia Brasileira de Letras, 1952. p. 205.

29 CASTELLO, José Aderaldo. Aspecto do romance brasileiro. Ministério da Educação e Cultura, s/d. p. 47-53.

30 CANDIDO, Antonio \& CASTELLO, José Aderaldo. Presença da Literatura Brasileira. 6. ed. Rio de Janeiro: DIFEL, 1976. p. 79. 
lo"31. Não mais a obra isolada nas situações narrativas, mas as circunstâncias de sua realização. Não mais a "falha da visão" do condicionamento social, mas o cuidado com o "vínculo entre a obra e o ambiente, depois de termos chegado à conclusão de que a análise estética precede considerações de outra ordem". Sem a dissociação das visões, há que

fundir texto e contexto numa interpretação dialeticamente integra, em que tanto o velho ponto de vista que explicava pelos fatores externos, quanto o outro, norteado pela convicção de que a estrutura é virtualmente independente, se combinam como momentos necessários do processo interpretativo. ${ }^{32}$

Nessa vertente, a sociologia da literatura e o comparativismo tentam aproximações entre as obras, apreendendo o objeto artístico, pela interpretação estética que assimila a dimensão social como fator de arte.

Alceu Amoroso Lima ${ }^{33}$, em estudos de contribuição à história do Modernismo literário, situa Alfredo Taunay e Euclides da Cunha no "balanço nacional". Ambos militares, em épocas e operações de objetivos diversos, legaram "grandiosas sínteses de nossa nacionalidade", apesar da impossibilidade de compará-los. De qualquer forma, se aquele nos deu "uma página imortal de dor e de heroísmo" da nacionalidade, este "as mais poderosas, as mais profundas, as mais grandiosas sinteses de nossa nacionalidade em esboço". Um, a "tragédia da consciência"; outro, a "tragédia da terra".

Nesse aspecto, na perspectiva dos universos distintos do regional em Alencar e em Taunay, José Maurício Gomes de Almeida ${ }^{34}$ privilegia um estudo minucioso sobre o sentido das epígrafes de Inocência, até então em total desatenção crítica. Elas constituiriam um artifício do narrador para "dialogar com a sua narrativa e, por via indireta, com o leitor”. Apesar das diferenças e da distância de trinta anos que os separam, a analogia das situações "trágicas" de páginas da história do Brasil está

31 CANDID0, Antonio [1957]. Formação da Literatura Brasileira (momentos decisivos). 8. ed. Belo Horizonte-Rio de Janeiro: Itatiaia, 1997. v. 2 (18361880), p. 99.

32 Idem. Literatura e sociedade: estudos de teoria e história literária. 8. ed. São Paulo: T. A. Queiroz, 2000. p. 3 e seguintes.

33 LIMA, Alceu Amoroso. Primeiros estudos: contribuição à história do Modernismo literário. Rio de Janeiro: Agir, 1948. p. 292.

34 ALMEIDA, José Maurício Gomes de. A tradição regionalista no romance brasileiro (1857-1945). Rio de Janeiro: Achiamé, 1981. p. 93-97. 
na facilidade de composição descritiva do regionalismo. Dessa forma, o regional deixa o "localismo redutor", para o alcance de uma "estética global". Ou seja, os sentidos percorrem o texto de dentro para fora e nas beiradas, no desejo de poder dizer em todos os quadrantes, inclusive nos universais.

Outros aspectos do potencial de universalidade contidos na narrativa de Alfredo Taunay chamam a atenção. Massaud Moisés ${ }^{35}$ e Temístocles Linhares ${ }^{36}$ destacam a construção dos tipos nos romances do escritor. 0 primeiro fala do "equilíbrio dialético" da narrativa de Inocência e "da cosmovisão de Taunay"; o outro atesta a "contribuição nova" aos novos rumos do sertanismo brasileiro, "não propriamente em favor de maior aproximação com a realidade, mas antes de mais rica e profunda imaginação na esfera criativa”. Wilson Martins ${ }^{37}$, como a reverter uma antiga polêmica entre Taunay e Alencar, sugere certa influência de Inocência sobre $O$ Sertanejo, que

repete, no título, na paisagem, nos caracteres e na ação, a temática inaugurada por Taunay, com Inocência, e que, como já foi observado, permaneceria para sempre no foco central do nosso regionalismo ${ }^{38}$.

Nesse vasto panorama crítico-historiográfico, Antonio Candido não se deixa levar pelas antigas cisões de estilos literários. Avaliando o horizonte da segunda metade do século XIX, inscreve a obra de Taunay no "nacionalismo literário". Considera-o um escritor que, como poucos, efetuou "levantamento tão cabal do país [...], na ficção e no documentário, só fez descrever as suas cidades e campos, a natureza e o homem, preocupado em registrar, depor, interpretar" ${ }^{39}$. Assim, o regionalismo será visto

35 MOISÉS, Massaud. História da Literatura Brasileira. São Paulo: Cultrix, 1985. v. II - Romantismo, p. 281.

36 LINHARES, Temístocles. História crítica do romance brasileiro (1728-1981). Belo Horizonte: Itatiaia; São Paulo: EDUSP, 1987. p. 155.

37 MARTINS, Wilson. História da Inteligência Brasileira. 2. ed. São Paulo: Cultrix, 1977. p. 508.

38 Alfredo Taunay não desmerecia o "enorme talento, grande força de trabalho e a pena dúctil e elegante" de Alencar, mas acusava-o de desconhecer a natureza brasileira "que tanto pretendia reproduzir nem dela estava imbuído", pois "descrevia-a do fundo do seu gabinete" TAUNAY, Alfredo d'Escragnolle. Memórias do Visconde de Taunay. São Paulo: Melhoramentos, 1948. p. 166.

39 CANDID0, Antonio [1957]. Formação da Literatura Brasileira (momentos decisivos). 8. ed. Belo Horizonte-Rio de Janeiro: Itatiaia, 1997, v. 2 (18361880), p. 266-282. 
como "programa e critério estético" que a "sensibilidade e o bom senso" de Taunay exprimiram, o que diferencia o escritor de outros regionalistas. A combinação do estético com o pragmatismo da formação fundamenta o conjunto da obra e dimensiona as características da sua personalidade.

\section{Um escritor de transição ou da tradição?}

Como se viu, Alfredo Taunay foi bastante referenciado pela crítica literária brasileira, encontrando-se no espaço de uma transição entre os estilos romântico e realista, especificamente na vertente da tradição regionalista do romance brasileiro. Regra geral, a preferência pelo possivel enquadramento fica no estilo romântico. Sua concepção de mundo tem muito de romântico, tanto pelo idealismo sentimental como pela observação e análise, sendo que estas duas últimas aparecem como predominantes. Isso se explica pela compreensão do tempo histórico e da função que sua obra exerceu no programa de disseminação das idéias nacionalistas.

A segunda metade do século XIX foi de um panorama propício ao desenvolvimento de idéias liberais no Brasil (formação de novos partidos políticos), abolicionistas (necessidade de substituição do trabalho escravo por mão-de-obra imigrante) e republicanas, todas elas abertas às influências positivistas européias e, ao mesmo tempo, permeadas pelas instabilidades políticas que vinham de longe, como o "fantasma” da Guerra da Tríplice Aliança contra o Paraguai. Movimentos que colocariam à mostra as contradições da sociedade brasileira e da América Latina, suplantadas pela idéia de Estado-Nação. Na obra Império e República, Taunay já considerava a diferença entre o regime imperial ante o mar de repúblicas:

0 que, antes do mais, distinguia o Brasil império era a segura e valente coesão de todas as suas partes constitutivas [...] mantínhamos essa admirável unidade de vistas e ideais num vastíssimo, mas bem ponderado organismo nacional, animado por larga e generosa circulação vital, impulsionada de um centro único, mas, irradiando para todas as direções, sem deixar ponto algum a que não levasse ou procurasse levar o benefício de sua influição atenta e justiceira. ${ }^{40}$

A distinção do Brasil, como o único organismo coeso na América Latina, representava um sentimento muito acima de todos os outros. É um sinal do conjunto equilibrado de forças

40 TAUNAY, Alfredo D’Escragnolle [1888]. Império e República. São Paulo:

Melhoramentos, 1933. p. 308, grifos meus. 
que liberta e que gera benefícios justos por todas as partes de sua vasta superfície, sem perder de vista a necessidade de adquirir a experiência dos povos mais avançados da civilização. A citação resume o conceito de Monarquia em contraposição à República. Aquele se distinguia pela segura e valente coesão de todas as partes constitutivas, apesar de vastas e mal povoadas; este, o falseamento dos ideais patrióticos, o desamor à terra. Nesse período Taunay analisava as conseqüências da política imperial e revitalizava a figura do tio-viajante Aimé-Adrien Taunay $^{41}$. Buscava documentos e comunicava-se com amigos, exercitando a compreensão de todo o período político já vivido, com o olhar da maturidade e das experiências vivenciadas.

Dessa forma, pode-se verificar como a noção de Império se imbricava na de Pátria. Por isso, um sentimento transformador muito presente em personagens de caráter forte, como o guia Lopes da retirada da Laguna - um homem simples, natural mas que, em determinado momento, é o ditador: "Pois bem! Lutaremos! Mas só daqui a pouco”, acrescentou, voltando-se para nós. "Primeiro vou enganar os paraguayos [...]; depois, desvio para a minha fazenda" ${ }^{2}$. A autenticidade com que descrevia as figuras humanas é determinante para o seu conhecimento de artista.

A noção de Estado Imperial como organismo nacional de coesão e unidade, tão decantada na segunda metade do século XIX, sugere a vinculação do pensamento de Taunay à tradição de que vimos tratando: familiar e ideológica, oriunda das academias e de sistemas de governo monárquicos europeus. A força do argumento imperial, em detrimento do republicano, soa referendada pelo propalado nacionalismo romântico, ao qual o escritor é ligado pela crítica, desde Sílvio Romero. Sem afastar tal hipótese, é possível antever o "conservadorismo" taunayano, vinculado a inclinações aristocráticas de acentuada marca renaniana ${ }^{43}$.

As observações sobre a singularidade da formação aprimorada de Alfredo Taunay vão, no futuro, desaguar na cons-

41 Cf. a obra A cidade de Matto-Grosso (antiga Villa Bella), o rio Guaporé e a sua mais ilustre victima: estudo histórico, publicada na Revista do Instituto Histórico e Geographico Brazileiro, Rio de Janeiro: Companhia Tipographica do Brazil, 1891. tomo LIV, parte I, p. 1-108. A 2a edição, preparada pelo filho Affonso Taunay, teve o título alterado para $A$ cidade do ouro e das ruinas: Matto Grosso, antiga Villa-Bella - o rio Guaporé e a sua mais illustre victima, pela Companhia Melhoramentos, 1923.

42 TAUNAY, Alfredo D’Escragnolle. A retirada da Laguna. Org. Sérgio Medeiros. São Paulo: Companhia das Letras, 1997. p. 160.

43 Cf. RENAN, Joseph Ernest. Que es una nación? Trad. Andrés de Blas Guerrero. Madrid: Alianza Editorial, 1987. p. 85. Cf., ainda, GURGEL, Leoncio do Amaral. O neto de Marco Aurélio (D. Pedro II). São Paulo: J. Fagundes, 1936. 
trução de um estilo único. 0 espírito particular de observação conduziu-o àquela objetividade que o colocou frente à cosmovisão realista. Vista por Olívio Montenegro ${ }^{44}$, essa excessiva objetividade é um traço negativo. Contudo, a fidelidade às origens, ao modelo clássico de composição, a frieza minuciosa da observação e o logicismo do seu pensamento, apurado pelo exercício da pintura, foram responsáveis pelo depuramento do poder de observação e de retenção do objeto, que não pode ser deixado de lado. Ou seja, o olho microscópico, magnetizado pela cor local, que deixa a impressão de homem de ciência, nada mais é do que a descida do tom no modo de o escritor relacionar-se com o objeto de sua obra, já fora dos rígidos padrões românticos idealizados. E mais uma vez, os mestres dessa objetividade foram os franceses, como escreve Alfredo Bosi:

Flaubert, Maupassant, Zola e Anatole, na ficção; os parnasianos, na poesia, e Comte, Taine e Renan, no pensamento e na História. Em segunda plana, os portugueses, Eça de Queiroz, Ramalho Ortigão e Antero de Quental, que travavam em Coimbra uma luta paralela no sentido de abalar as velhas estruturas mentais. ${ }^{45}$

Forma-se, assim, com esses escritores citados, especificamente o filósofo Renan, um campo de entrecruzamento de diversas correntes estéticas, atravessadas pelo "filete romântico-simbolista", de que fala Afrânio Coutinho, por entender que o século XIX foi uma época de tantas rupturas e transformações que a periodização precisa é plenamente recusada. Principalmente no Brasil, o novecentos adquiriu caráter de um "fenômeno" específico, fecundamente influenciado pela visão ideológica renaniana. Nesse aspecto, continua o crítico,

torna-se mais corriqueiro dadas as circunstâncias naturais de sua vida na época, em virtude do atraso com que sempre repercutem entre nós os movimentos espirituais, e ainda porque as transformações aqui não se realizam organicamente, de dentro para fora, como resultados da própria evolução da consciência nacional, mas como reflexo de idéias-forças de origem estrangeira. ${ }^{46}$

44 MONTENEGRO, Olívio. O romance brasileiro. 2. ed. Rio de Janeiro: José Olympio, 1953. p. 71-78.

45 BOSI, Alfredo. História concisa da literatura brasileira. São Paulo: Cultrix, 1988. p. 186, grifos meus.

46 COUTINHO, Afrânio. Introdução à literatura no Brasil. Rio de Janeiro: Livraria São José, 1966. p. 180. 
As especificidades brasileiras dificultavam (e ainda dificultam) a relação íntima entre os elementos intrínsecos que constituíam a cultura nacional, impedindo o amálgama do todo orgânico, o caráter autóctone tão necessário ao cumprimento dos preceitos ditados pelos primeiros observadores sociais. De fato, a repercussão das variadas idéias se deve, provavelmente, à diversidade de grupos representantes das várias regiões, não sendo possível construir uma evolução simplificada, nem é o nosso propósito neste texto. 0 que nos interessa é a consciência da medida exata com que Alfredo Taunay soube conciliar o engenho da construção de uma idéia e a arte da composição narrativa.

Nesses dois pólos que em sua obra se complementam, nenhuma imagem se acumula, porém elas se unem no universo de construção harmônica da propensão às coisas do espírito, como atesta nas Memórias: "era eu o único dentre os companheiros e, portanto, de toda a força expedicionária que ia olhando para os encantos dos grandes quadros naturais e lhes dando o devido apreço" ${ }^{\text {47 }}$. Tal construto tem início com a viagem e amadurece no processo de (re)elaboração posterior.

0 exercício da observação vai conformando uma concepção de que o sertão é um lugar sem moradias porque, quanto mais o movimento humano adentra na geografia do local, mais o cenário e os costumes se modificam, fechando-se em tradições e em respeito aos valores morais, como se vê em Inocência. Esses "filhos da natureza" ${ }^{48}$ dizem pouco e observam muito, o que constitui uma característica do povo brasileiro do interior, registrada em estudos de Augusto César Proença ${ }^{49}$ e de Abílio Leite de $B \operatorname{rrros}^{50}$, que tratam da índole desconfiada do pantaneiro, como elemento cultural.

Filho das paragens bárbaras, o sertanejo de Mato Grosso se faz pelo exercício intenso da bravura e da força. Como nos primeiros tempos, o pequeno número de povoadores contrasta

47 TAUNAY, Alfredo d'Escragnolle. Memórias do Visconde de Taunay. São Paulo: Melhoramentos, 1948. p. 131, grifos meus.

48 SCHLICHTORST, C. A Literatura no Brasil. In: Historiadores e Críticos do Romantismo. A contribuição européia: crítica e história literária. Seleção e apresentação de Guilhermino César. São Paulo: EDUSP, 1978. p. 101.

49 PROENÇA, Augusto César. Pantanal: gente, tradição e história. Campo Grande-MS: Ed. UFMS, 1997.

50 BARROS, Abílio Leite de. Gente pantaneira. Rio de Janeiro: Lacerda Ed., 1998. 
com a vastidão da terra, num convívio com o povo autóctone, o indígena, em número já reduzido na segunda metade do século XIX. Formou-se, assim, um traço de originalidade muito bem captado na descrição de tipos como Cardoso Guaporé, o guia Lopes, a índia guaná, Juca, o tropeiro, configurando a diversidade étnica que marcou a tipologia mato-grossense.

A preocupação com detalhes realistas, na descrição das personagens e da paisagem, coloca o olhar do artista entre as impressões neoclássicas, com impulsos racionais diante do mundo (e aí residem os legados familiares, a influência dos componentes da missão artística de 1816, estudos e vinculações com outros cientistas) e da emoção romântica, elevada à expressão máxima.

Visto desta maneira, perguntaria: em que sentido o neoclássico entra na composição dessa nova sensibilidade artística?

De modo genérico, o neoclássico é uma tentativa de recuperação do ideal greco-latino de arte e de vida, que foi revisitado no Renascimento e no Arcadismo. É uma arte da mimesis, cujo princípio estabelece a relação entre o mundo real e o ideal, criando o kosmos. Simultaneamente, embora Taunay abarque parte significativa da realidade e suas formas cotidianas, em variadas misturas de impressões, a sua intenção ultrapassa a representação desse real. Seu intento abrange uma realidade, contudo a sobrepuja também, o que é visível no estilo, na linguagem e na estrutura interna da obra. Não é só mera posse da realidade, mas certa dose de transgressão dela, produzindo um mundo particular, também alternativo para se pensar o Brasil daquele momento.

Assim, a concepção neoclássica de Taunay está ligada não mais à arte rígida dos antigos protótipos, porém à "reconstrução" deles; a arte não como intuição do mundo, mas um "estado de recolhimento e reflexão", como vista por Giulio Carlo Argan ${ }^{51}$. Ou seja, do ideal artístico, dirigido ao intelecto, a arte volta-se para os sentimentos, para o ethos. Por isso, os românticos falam de povo e restituem um fundamento ético ao trabalho humano, intensificado nos subterrâneos das contradições realistas. 0 liame que se estabelecia entre o escritor e o mundo não falseou os propósitos da forma, como ela se apresenta aos sentidos. Não mais um modelo clássico, e sim uma representação do espírito ligada à ação dinâmica das forças elementares da natureza e do povo. Nesse sentido, à concepção romântica de mundo aliam-se vinculações clássicas, marcadas pela formação do nosso escritor.

51 Cf. ARGAN, Giulio Carlo. Arte Moderna. Trad. Denise Bottmann \& Frederico Carotti. São Paulo: Companhia das Letras, 1992. p. 25-28. 
No Brasil, essas tendências artístico-literárias andaram juntas, diferentemente do que aconteceu na Europa. Taunay foi tomado por singularidades adquiridas no contato com novas experiências, já reconhecidas desde as bases teóricas propostas por Ferdinand Denis, garantindo o tema e o material que conformavam a existência de uma cultura eminentemente brasileira e monárquica. Denis propunha as bases da "brasilidade", no sentido da busca do genuinamente brasileiro, isto é, da natureza exótica e pitoresca. Com essa postura, contribuiu para a primeira construção da imagem da nossa identidade.

Nessa esteira, pelas obras de Taunay é possível reorientar o foco da análise para o sentido da representação de um ideal estético. Ou seja, os estilos artístico-literários, que permeiam a produção do escritor, são pistas de tendências que representam uma singularidade ainda não totalmente explorada na época - o interior brasileiro. Nessa associação de elementos, a ocupação de um espaço interior no continente sul-americano transformou-se num projeto colonizador, ampliado, nos séculos seguintes, para um projeto híbrido cultural. 0 espaço das infinitas possibilidades de sentidos, mesmo muito diversas e distantes, permite estimular posturas assumidas pelo artista, em relação à história e à realidade natural e social. Desta forma, aqui, o sentido de transição em Taunay não se refere apenas àquela do tipo do Romantismo para o Realismo ou da criação da imagem de nação anterior ao Romantismo e pós-guerra da Tríplice Aliança, mas a um "divisor de águas" desse momento histórico e cultural ${ }^{52}$. É mais uma preocupação de explorar, pela crítica sobre o autor, a construção de uma imagem do interior brasileiro, no século XIX, contribuindo para as discussões mais urgentes sobre temas artísticos, culturais e de projeto político-literário, no sentido que o escritor tentou dar à formação da nacionalidade.

\section{Taunay viajante: construção ou missão?}

Convém ressaltar o saldo positivo (pelo menos no que diz respeito à formação do escritor) que a participação como relator na guerra trouxe para Alfredo Taunay. Nomeado para redigir os acontecimentos, como secretário da Comissão de Engenheiros, esse encargo proporcionou-lhe as vivências mais significativas da viagem.

52 MARETTI, Lídia Lichtschdl. Um polígrafo contumaz: o Visconde de Taunay e os fios da memória. 1996. Tese (Doutorado em Teoria Literária) - Instituto de Estudos da Linguagem, Universidade Estadual de Campinas, 1996. p. 57. 
Uma questão surge neste ponto da reflexão: por que um filho da elite brasileira se embrenhou pelos sertões do interior brasileiro?

Por incentivo dos pais a quem a carreira militar era a única para um "homem superior" ${ }^{53}$, por orgulho de moço recémformado, ou por necessidade de vivenciar a aventura da viagem numa guerra que estava pensada para terminar rapidamente (fato que arbitrariamente não ocorreu), Taunay foi nomeado por um pedido pessoal do pai ao Imperador:

Estava o Imperador despachando uns papéis [...] quando meu pai apareceu. Contou a que ia ao imperial amigo e, depois de verificado com o habitual escrúpulo, que tal ato não ia de encontro a lei nenhuma positiva, foi ali mesmo assentada a minha nomeação de ajudante da comissão de engenheiros junto às forças destinadas a Mato Grosso. ${ }^{54}$

Relações frutíferas para Taunay facultaram-lhe menos dissabores durante a viagem. Talvez por uma deferência especial, comprou (e continuou recebendo) alguns materiais úteis, o que, em várias situações narrativas, registrou com "inexcedível préstimo". Além das freqüentes doses de quinino enviadas pelo pai,

essas malas [malinhas de cangalha] com a competente cama; esplêndida barraca forrada que me foi dada pelo Arsenal da Corte; um par de botas altas, de couro da Rússia, que comprei na loja do Queirós por sessenta mil réis. Pelos serviços prestados valia bem o triplo ou quádruplo. ${ }^{55}$

Por outro lado, a idéia de viver uma vida própria, de criar e se entregar aos prazeres da novidade trazida pela viagem, tinha o gosto da transformação e do desconhecido, motivo suficiente para mover o jovem militar às aventuras: "Todo o interior do Brasil se abria ante os nossos passos, nada mais, nada menos, e, certamente, a vastidão tem em si inúmeros atrativos e grandioso prestígio [...]" ${ }^{\prime 56}$.

53 TAUNAY, Alfredo d'Escragnolle. Memórias do Visconde de Taunay. São Paulo: Melhoramentos, 1948. p. 69.

54 Ibid. p. 69.

55 Ibid. p. 69.

56 Ibid. p. 105.

revista do ieb n 46 fev 2008 
Caberia, então, a Taunay-viajante, desenvolver as aptidões, de alguma forma, de um civilizador. Não só se deixar levar pelas benesses da viagem, mas desenvolver o conhecimento, carregando, portanto, a missão de cumprir as regras de um projeto. A narrativa de viagem toma forma de conteúdo intrínseco no processo de fundação da nacionalidade, do resumo de uma imagem do interior do Brasil à época, parte do complexo sistema de identificação da idéia de nação.

A literatura e a política ocuparam a curiosidade de Alfredo Taunay e, ao que parece, governaram suas ambições. Nos primeiros anos, a literatura predominou através da experiência da viagem. 0 conhecimento de/sobre o Brasil fez dele um atuante político. Nesse aspecto, das leituras dos clássicos da meninice às influências filosófico-artísticas, o menino foi-se formando dentro de preceitos rígidos de comportamento, dignos da elite brasileira da época; e, mesmo participando da cúpula Imperial, circulava entre idéias avançadas como as de Joaquim Nabuco, Carlos Gomes e André Rebouças, defensores de reestruturação da sociedade brasileira.

Outro aspecto pode ser analisado do comportamento do escritor. Havia nele uma espécie de atitude missionária que extrapolava o seu livre arbítrio de jovem militar:

Naquela ocasião, fins de fevereiro (acabava eu de fazer 22 anos) e princípios de março, estava se organizando uma expedição que devia seguir por terra a dar execução ao plano de atacar-se a República do Paraguai pelas suas duas fronteiras meridional e setentrional, entrando as colunas de um lado por Corrientes e do outro pelo distrito de Miranda, em Mato Grosso, e zona do Apa, plano muito razoável no gabinete e à vista de mapas que simplificam tudo, enormes distâncias, fornecimento de víveres e o mais, mas cuja realização era quase impraticável. ${ }^{57}$

Sem ser muito afeito às milícias, Taunay se alistou numa guerra de planejamento "de gabinete", numa região “impraticável” pela insalubridade e variação constante do ciclo das águas, o que constituiu uma participação intrigante. Movido pelo ideal ou pelo desejo de honrarias e de condecorações de carreira, o seu comportamento pode ser visto como protótipo de um tempo. Pela capacidade de sublevar os compromissos, a

57 TAUNAY, Alfredo d'Escragnolle. Memórias do Visconde de Taunay. São Paulo: Melhoramentos, 1948. p. 91, grifos meus. 
incursão de Taunay nos sertões de Mato Grosso enquadra-se também numa atitude aristocrática de elevação do espírito, mais do que um simples compromisso militar ${ }^{58}$. Não fosse pela ética e pelo senso de responsabilidade social e nacional, talvez ele se tivesse furtado dessa viagem ${ }^{59}$. ético?

Mas o que explicaria tal comportamento aristocrático e

Inicialmente, essas atitudes poderiam apenas ser "germes de origem", que depois foram fortalecidos pela experiência e pelo exercício da própria profissão. Se não, vejamos. Em sentido estrito, o dicionário nos dá o conceito de aristocracia como um tipo de organização social e política em que o governo é monopolizado por uma classe privilegiada, a dos fidalgos, que se distinguem pelo saber e merecimento real $^{60}$. De forma mais abrangente, o conceito de aristocracia, tomado na compreensão do ideal monárquico, tem inspiração renaniana de "responsabilidade moral das elites" 61 . Passemos a ele pelo viés do sentido de nação segundo o próprio pensador Renan.

Para Joseph Ernest Renan, o sentido de nação é resumido como "princípio espiritual", valores, costumes e educação, "transmitidos" hereditariamente. De certa forma, esse conceito contradiz os princípios românticos de que a História é processo dinâmico, resultante da ação de forças em perpétua mutação e adaptação. Opõe-se, nesse aspecto, a Ferdinand Denis que, acompanhando Herder, acreditava na grandeza do país pelo espírito de raça, isto é, que os melhores homens fazem grandes impérios ${ }^{62}$.

58 Em Notas de um desbocado (Entrevista a Elias Thomé Saliba, n'O Estado de São Paulo, Caderno 2, 27/03/05), o antropólogo Sérgio Medeiros diz que Taunay, pelo seu espírito contemplativo, comportou-se mais como amante das belezas naturais do que como soldado.

59 Odilon Matos (em 0 monarquismo de Taunay, Jornal A federação. Itu-SP, 6/06/1992) escreve que, "se o segundo Imperador do Brasil não fosse D. Pedro II, o Visconde de Taunay, provavelmente, seria republicano [...], demonstrando preocupações bastante evoluídas, muito mais do que qualquer outro político do Império" (grifo meu).

60 FERREIRA, Aurélio Buarque de Holanda. Novo dicionário da Língua Portuguesa. Rio de Janeiro: Nova Fronteira, 1975. p. 132.

61 Cf. BERRIEL, Carlos Eduardo Ornellas. Tietê, Tejo, Sena: a obra de Paulo Prado. Campinas-SP: Papirus, 2000. p. 34 e 161.

62 Sobre as idéias herderianas, cf. GARDINER, Patrick. Herder: Idéias para a filosofia da história da humanidade. In: GARDINER, Patrick (Org.) Teorias da História. Trad. Vítor Mato e Sá. 3. ed. Lisboa: Fundação Calouste Gulbenkian, 1984. p. 43-59. 
0 grupo de D. Pedro II era tido como ligado a essa teoria da História. Não era gratuito, portanto, que Marco Aurélio ${ }^{63}$ fosse tomado como protótipo da idéia de que "una agregación de hombres, sana de espíritu y calidad de corazón, crea una consciencia moral que se llama nación" ${ }^{4}$. 0 estóico Imperador romano simbolizava o "reitor da nacionalidade". A sua figura era o "alicerce espiritual", em que se poderia construir uma nação, da mesma forma como se consolidou a imagem de D. Pedro II durante todo o seu longo reinado.

Nação teria, então, dois princípios: um da alma, conseqüência de um passado heróico, de grandes homens e de glórias comuns; outro constituído por "sentimento de sacrifícios" em prol de uma grande comunidade solidária, "la existencia de una nación es (perdone esta metáfora) um plebiscito de todos los días, del mismo modo que la existencia del individuo es una perpetua afirmación de vida"65. Desta forma, o espirito de sacrificio missionário, aliado ao convívio com a elite dos círculos do poder, à formação familiar e militar, com suas bases de convicção política, mobilizou Alfredo Taunay. Sem contar que a participação na guerra era motivo de glória e de fama, o que, para um jovem militar, "de feições vaidosas" estar acima de qualquer outra manifestação visível.

No entanto, vamos destacar o aspecto do pensamento da época, quando as idéias de Renan, mesmo representando o passadismo morto, se adequavam mais aos lugares considerados atrasados como o Brasil. A sua obra teve importância histórica na representação da necessidade de manutenção do passado, propícia para justificar a Monarquia brasileira. Tornou-se, assim, "intérprete daqueles que procuravam firmar o conceito de sentimento nacional”, no momento de desagregação e rupturas sociais. Sobrelevando o conceito de aristocracia, Renan reafirmava a idéia dos "homens melhores que constroem uma civilização"67. Residia aí a autenticidade da formação do nacional.

63 Cf. o ensaio de GURGEL, Leoncio do Amaral. O neto de Marco Aurélio (D. Pedro II). São Paulo: J. Fagundes, 1937.

64 Cf. RENAN, E. Que és una nación? Trad. Andrés de Blas Guerrero. Madrid: Alianza Editorial, 1987. p. 85.

65 Idem. p. 83.

66 TAUNAY, Alfredo d'Escragnolle. Memórias do Visconde de Taunay. São Paulo: Melhoramentos, 1948. p. 71.

67 Cf. BERRIEL, Carlos Eduardo Ornellas. Tietê, Tejo, Sena: a obra de Paulo Prado. Campinas-SP: Papirus, 2000. p. 34. 
De forma semelhante, em muitos trechos das narrativas da viagem a Mato Grosso, Taunay traduz determinados princípios do espírito de abnegação e de heroísmo do soldado brasileiro, superior a todas as situações de conflito e de dificuldades: "Os soldados caem mortos pelo caminho e seus corpos são devorados pelos corvos. São as nossas misérias infindas. Todos, no entanto, comportam-se com "inexcedivel heroísmo" 0 heroísmo é somado ao sentimento de colaboração e de despojamento do sertanejo, cujos sofrimentos são amenizados pela partilha, longe dos recursos, sobretudo quando relembra a ajuda que tiveram:

A solicitude com que esses ex-fazendeiros se empenharam em nos agasalhar bem e festejar-nos foi suave compensação, após tantos sofrimentos suportados com resignação e coragem acima de nossas forças. ${ }^{69}$

Nessa perspectiva, ao participar da campanha contra o Paraguai, Taunay assumiu, aristocraticamente, do alto da postura de "homem superior", uma tarefa missionária para contribuir com o alargamento e a manutenção dos ideais monárquicos. A serviço do Estado ou da Arte, transformou o sertão em objeto de uma experiência estética, fornecendo material para a compreensão do complexo cultural e político brasileiro. Soldado exemplar, Taunay trazia, na bagagem, os germes do que se transformaria no futuro em político, literato e artista ${ }^{70}$, tocando mais ou menos intensamente em outros campos como romance, conto, drama, jornalismo, oratória, narrativas de viagem, magistério, música, crítica musical, história, lingüística.

68 TAUNAY, Alfredo d'Escragnolle. Cartas de Campanha de Mato Grosso 18651866. Rio de Janeiro: Edição da Biblioteca Militar, 1944. p. 165.

69 Ibid. p. 154.

70 Lemos nas Memórias (1948) que Taunay compôs uma peça ao piano, Thomas m'endort, Thomas m'éveille (Tomás me faz dormir, Tomás me acorda), e escreveu "contozinhos" e fábulas, em 1853. Tomás era um pajem (escravo), "companheiro de meninice e depois auxiliar da casa" que participava das brincadeiras e travessuras infantis e [...] "de manhã procurava levantar-me antes de todos, correndo de pés no chão para ir fazer a apetecida colheita” [...]. (TAUNAY, Alfredo d'Escragnolle. Memórias do Visconde de Taunay. São Paulo: Melhoramentos, 1948. p. 17; 22). Sua primeira publicação foi aos 15 anos no jornal $O$ Tamoio (1858), quando cursava o colégio Pedro II, no Rio de Janeiro (p. 57). 
A junção desses elementos formadores do homem Taunay e de sua vasta obra pode ser vista como exemplar da tentativa de caracterizar a terra brasileira e representar um período histórico de transformações sociais e rupturas ideológicas, como as que foram sentidas, ainda em vida, por Taunay e sob uma visão pessimista de um novo tempo.

Não vendo com bons olhos o regime republicano, Taunay chegou a presenciar a decadência dos novos tempos, tendo publicado algumas obras que trazem à tona essas questões, como Império e República e Memórias.

Sair da Corte para conhecer outros lugares e viver outras experiências possibilitou a Taunay incorporar o novo e operar conceitos, um trabalho que chegou a desenvolver pouco. No entanto, suas obras mais significativas sobre Mato Grosso representam o entrecruzamento de imagens (mental e/ou visual) que enunciam um outro, distante no espaço e no tempo. Em outras palavras, as representações sobre Mato Grosso não são reflexo do real, mas identificação de um lugar reconhecido pelo material criteriosamente selecionado e reagrupado dentro de uma nova escala de significações. 0 escritor coloca-se, portanto, no "entremundos", ou no "entre-lugar"71, resultando daí a proliferação das imagens recriadas.

71 SANTIAG0, Silviano. Vale quanto pesa (a ficção brasileira modernista). Rio de Janeiro: Paz e Terra, 1982. p. 25-40 (mimeo). 